\title{
Development of a microtitre plate-based assay for lipid-linked glycosyltransferase products using the mycobacterial cell wall rhamnosyltransferase $\mathrm{WbbL}$ \\ Correspondence \\ Michael R. McNeil \\ mmcneil@colostate.edu \\ Received 15 August 2008 \\ Revised 9 September 2008 \\ Accepted 11 September 2008 \author{
Avraham Liav ${ }^{1}$ and Michael R. McNeil ${ }^{1}$ \\ ${ }^{1}$ Department of Microbiology, Colorado State University, Fort Collins, CO 80523, USA
${ }^{2}$ Dalian Medical University, Dalian, PR China
} \\ Anna E. Grzegorzewicz, ${ }^{1}$ Yufang Ma, ${ }^{1,2}$ Victoria Jones, ${ }^{1}$ Dean Crick, ${ }^{1}$ \\ In Mycobacterium tuberculosis a rhamnosyltransferase ( $\mathrm{WbbL}$ ) catalyses the transfer of an $\alpha-\mathrm{L}-$ Rhap residue from dTDP-L-rhamnose (dTDP-Rha) to decaprenyldiphosphoryl- $\alpha$-D- $N$ - acetylglucosamine (GlcNAc-P-P-DP) to form $\alpha$-L-Rhap- $(1 \rightarrow 3)-\alpha$-D-GlcNAc-P-P-DP, which is then further elongated with Galf and Araf units, and finally mycolylated and attached to the peptidoglycan. This enzyme is essential for M. tuberculosis viability and at the same time absent in eukaryotic cells, and is therefore a good target for the development of new antituberculosis therapeutics. Here, we report a microtitre plate-based method for the assay of this enzyme using a crude membrane preparation from an Escherichia coli strain overexpressing wbbL as an enzyme source and the natural acceptor substrate GlcNAc-P-P-DP. Initial characterization of the enzyme included unequivocal identification of the product Rha-GlcNAc-P-P-DP by liquid chromatography (LC)-MS, and the facts that WbbL shows an absolute requirement for divalent cations and that its activity is stimulated by $\beta$-mercaptoethanol. Its $\mathrm{pH}$ optimum and basic kinetic parameters were also determined, and the kinetic analysis showed that WbbL uses a ternary complex mechanism. The microtitre plate-based assay for this enzyme was developed by taking advantage of the lipophilic nature of the product. This assay should be readily transferable to other glycosyltransferases which use lipid-based acceptors and aid greatly in obtaining inhibitors of such glycosyltransferases for new drug development.
}

\section{INTRODUCTION}

Many bacterial glycosyltransferases (GTs) involved in cell wall biosynthesis transfer a sugar from a sugar nucleotide to a lipid (often polyisoprene)-containing acceptor. The $\mathrm{N}$ acetylglucosamine (GlcNAc) transferase MurG is a key peptidoglycan synthetic enzyme that utilizes a lipidcontaining acceptor (Mengin-Lecreulx et al., 1991). Another important example in Gram-positive bacteria is TagA (Zhang et al., 2006), by which an $N$-acetylmannosamine is attached to an undecaprenyl diphosphate-linked GlcNAc. In the mycobacterial cell wall the biosynthesis of the polymer arabinogalactan, which connects the peptidoglycan and mycolic acid layers, occurs on the lipid decaprenyl phosphate (DP) (Mikusova et al., 1996). Here, a rhamnosyl residue is attached to a decaprenyl diphosphatelinked GlcNAc by the rhamnosyltransferase WbbL (Mills et al., 2004). Convenient and inexpensive assays to search for

Abbreviations: DP, decaprenyl phosphate; dTDP-Rha, dTDP-L-rhamnose; ESI, electrospray ionization; GICNAc-P-P-DP, decaprenyldiphosphoryl- $\alpha-D-N$-acetylglucosamine; GT, glycosyltransferase; LC, liquid chromatography; TB, tuberculosis. inhibitors of such enzymes are lacking, and using WbbL we describe herein the development of such an assay.

The $w b b L$ gene is found in the genome of all mycobacteria. The protein sequence of this enzyme does not show homology to other rhamnosyltransferases in mycobacteria that synthesize various glycolipids. Previous studies with the temperature-sensitive mutant of Mycobacterium smegmatis $\mathrm{mc}^{2} 155$ (Mills et al., 2004) have shown that WbbL is essential for mycobacterial viability. The incubation of the temperature-sensitive mutant at the non-permissive temperature results in bacteria which cannot be recovered at the lower permissive temperature, suggesting that the inactivation of WbbL is a lethal defect (Mills et al., 2004). Therefore, a facile assay for its activity is particularly important in the development of new tuberculosis (TB) drugs.

The substrates for WbbL are dTDP-L-rhamnose (dTDPRha) and decaprenyldiphosphoryl-D- $N$-acetylglucosamine (GlcNAc-P-P-DP) (Fig. 1). GlcNAc-P-P-DP has hitherto not been available, and all assays for WbbL have been done using crude membranes that contain the GlcNAc-1-P transferase WecA and endogenous DP, which allows the in 

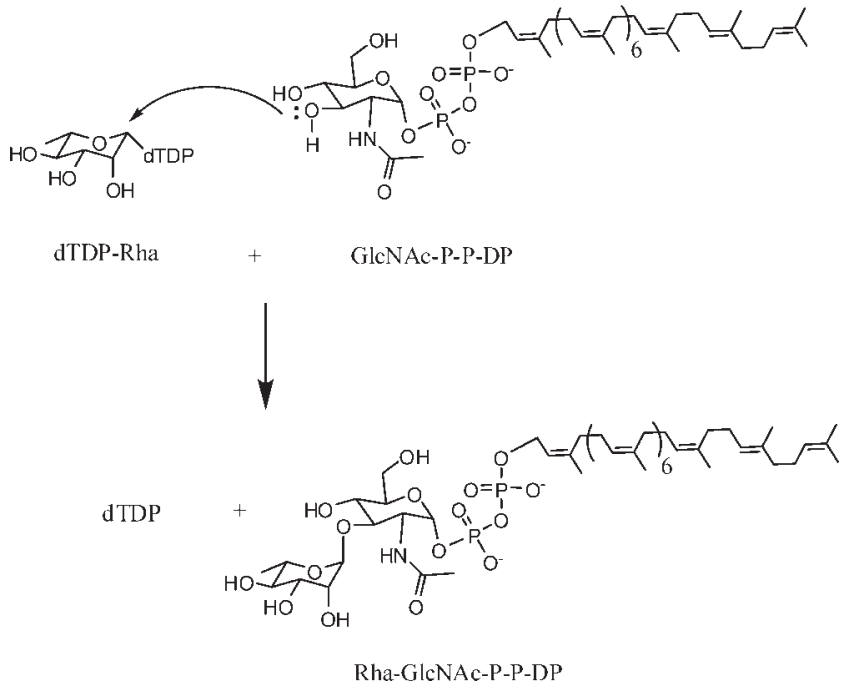

Fig. 1. The reaction catalysed by rhamnosyltransferase (WbbL).

situ preparation of the GlcNAc-P-P-DP acceptor when UDP-GlcNAc is provided. Although such assays have been used to identify the gene encoding WbbL (Mills et al., 2004), they are clearly inadequate to characterize the enzyme and to develop specific assays for its activity. Using WbbL substrates directly, we describe for what is believed to be the first time the characterization of WbbL in terms of $\mathrm{pH}$ optimum, ion dependence and kinetics, and then go on to describe the development of a microtitre plate-based assay for its activity that takes advantage of the lipid nature of the enzyme product.

\section{METHODS}

PCR, cloning, and expression. The DNA sequence of the Mycobacterium tuberculosis wbbL gene (906 bp) was acquired from the M. tuberculosis genome database (http://genolist.pasteur.fr/ TubercuList/). $M$. tuberculosis $w b b L$ was amplified from $M$. tuberculosis H37Rv genomic DNA by Vent DNA polymerase (New England Biolabs) using CATATGGTAGCGGTGACCTAC and GGATCCTCAGTGCCGCCCTTC primers. NdeI and BamHI sites in the primers facilitated cloning into plasmid pSTBlue 1 . The resulting pSTB-Mtb $w b b L$ plasmid was digested by NdeI and BamHI, and the $w b b L$ gene was ligated into the NdeI and BamHI sites of plasmid pET16b, yielding the expression vector pET16b-Mtb $w b b L$. For expression, pET16b-Mtb $w b b L$ was transformed into the following Escherichia coli strains: BL21[DE3] (Novagen), BL21[DE3]pLysS (Novagen), BL21[DE3] codon plus (Novagen), C41DE3 (Miroux \& Walker, 1996), Arctic Express (Stratagene), ER2566 (New England Biolabs), and BL21[DE3] containing pKJE7 (Takara Mirus Bio). Expression from pET16b in E. coli (ER2566) produced substantial WbbL in the membrane fraction and was used in further studies.

Cells (E. coli ER2566) were grown at $37{ }^{\circ} \mathrm{C}$ in LB medium containing $100 \mu \mathrm{g}$ ampicillin $\mathrm{ml}^{-1}$ until the culture reached $\mathrm{OD}_{600} 0.6$, and were then induced with $0.5 \mathrm{mM}$ IPTG for $4 \mathrm{~h}$ at room temperature. The cells were harvested, then resuspended in $100 \mathrm{mM}$ TAPS buffer, $\mathrm{pH}$ 8.6, containing $5 \mathrm{mM} \beta$-mercaptoethanol and $10 \mathrm{mM} \mathrm{MgCl}_{2}$ (buffer 1) and broken by French press. The broken cells were centrifuged at $20000 \mathrm{~g}$ for $10 \mathrm{~min}$ and the obtained supernatant was ultracentrifuged at $100000 \mathrm{~g}$ for $2 \mathrm{~h}$. The pellet containing the membrane fraction was homogenized in buffer 1 and stored at $-80{ }^{\circ} \mathrm{C}$.

SDS-PAGE. SDS-PAGE was run using $12 \%$ gels, and proteins were visualized with Coomassie brilliant blue and analysed by Western blotting using monoclonal anti-polyhistidine antibody (mouse IgG2a isotype; Sigma) as the first antibody and anti-mouse-IgG-alkaline phosphatase conjugate antibody (Sigma) as the second antibody.

dTDP-Rha and dTDP- $\left[{ }^{14} \mathbf{C}\right] \mathbf{R h a}$ preparation. dTDP-Rha was made from dTDP-Glc (Sigma-Aldrich) using recombinant RmlB (conversion to dTDP-4-keto-6-deoxy-D-xylohexulose), RmlC (di-epimerization to form dTDP-4-keto-6-deoxyl-L-lyxo-hexulose) and RmlD (reduces the 4-keto group to form dTDP-Rha) (Mills et al., 2004). The standard $1 \mathrm{ml}$ reaction mixture contained $1.2 \mathrm{mM}$ dTDP-Glc, $1.8 \mathrm{mM} \mathrm{NADPH}, 20 \mathrm{mM} \mathrm{MgCl}_{2}, 53 \mu \mathrm{g} \mathrm{RmlB}$ from Salmonella typhimurium, $13 \mu \mathrm{g} \mathrm{RmlC} \mathrm{(M.} \mathrm{tuberculosis)} \mathrm{and} 5 \mu \mathrm{g} \mathrm{RmlD}$ (M. tuberculosis) in $200 \mathrm{mM}$ Tris/ $\mathrm{HCl}, \mathrm{pH}$ 7.5. After $1 \mathrm{~h}$ incubation at $30{ }^{\circ} \mathrm{C}$, the reaction mixture was centrifuged using an Amicon Microcon with $10 \mathrm{kDa}$ cut-off membranes to remove proteins. dTDP-Rha was purified by HPLC on a Dionex column (CarboPac, PA-100). The HPLC flow rate was $2 \mathrm{ml} \mathrm{min}^{-1}$ and a gradient from 0 to $500 \mathrm{mM}$ triethylammonium acetate over $30 \mathrm{~min}$ was applied. The fractions were monitored by reading $A_{260}$ and checked by analytical HPLC (isocratic gradient of $200 \mathrm{mM} \mathrm{KH} \mathrm{PO}_{4}$ ). The retention times for dTDP-Rha and dTDP-Glc were 5.74 and 6.52, respectively. The fractions containing dTDP-Rha were pooled and lyophilized. For quantification of dTDP-Rha, alditol acetates were prepared and analysed by GC-MS. dTDP- $\left[{ }^{14} \mathrm{C}\right] \mathrm{Rh}$ a was made as described elsewhere (Mills et al., 2004). Briefly, $\left[{ }^{14} \mathrm{C}\right]$ sucrose (American Radiolabelled Chemicals) was converted to $\left[{ }^{14} \mathrm{C}\right] \mathrm{Glc}-1-\mathrm{P}$ by commercially available sucrose phosphorylase. Subsequently, $\left[{ }^{14} \mathrm{C}\right] \mathrm{Glc}-1-\mathrm{P}$ and TTP were converted to dTDP- $\left[{ }^{14} \mathrm{C}\right] \mathrm{Glc}$ by RmlA. The conversion of dTDP$\left[{ }^{14} \mathrm{C}\right]$ Glc to dTDP- $\left[{ }^{14} \mathrm{C}\right] \mathrm{Rha}$ and subsequent purification were performed as described above for non-radioactive dTDP-Rha.

Enzymic synthesis and purification of GICNAC-P-P-DP. Enzymic synthesis of GlcNAc-P-P-DP was adopted from Rush et al. (1997). GlcNAc-P-P-DP was synthesized from DP (Indofine) and UDPGlcNAc using WecA enzyme. The membranes overexpressing WecA enzyme were prepared as described elsewhere (Hyland \& Anderson, 2003). The reaction mixture contained $0.5 \mathrm{mg}$ membrane protein, $50 \mathrm{mM}$ Tris, $\mathrm{pH} 8.0,5 \mathrm{mM} \beta$-mercaptoethanol, $40 \mathrm{mM} \mathrm{MgCl}_{2}$, $0.5 \%$ CHAPS, $1 \mathrm{mM}$ sodium orthovanadate, $4 \mathrm{mM}$ UDP-GlcNAc and $2 \mathrm{mM}$ DP in a total volume of $0.5 \mathrm{ml}$. After incubation for $1.5 \mathrm{~h}$ at $30{ }^{\circ} \mathrm{C}$, the reaction was quenched by the addition of $7 \mathrm{ml}$ chloroform: methanol $(2: 1, \mathrm{v} / \mathrm{v})$ and shaken at room temperature for $20 \mathrm{~min}$. After addition of $500 \mu \mathrm{l}$ water, the organic layer was dried. The organic fraction was dissolved in $0.2 \mathrm{ml} 0.2 \mathrm{M} \mathrm{NaOH}$ in $\mathrm{CH}_{3} \mathrm{OH}$ and incubated for $20 \mathrm{~min}$ at $37{ }^{\circ} \mathrm{C}$ (Mikusova et al., 1996). After neutralization of $\mathrm{NaOH}$ with $5 \mu \mathrm{CH}_{3} \mathrm{COOH}$, the reaction mixture was dried and resuspended in $1.75 \mathrm{ml}$ chloroform : methanol: water $(4: 2: 1$, by vol.). After extraction, the organic layer was dried and applied to an aluminium oxide column $(0.5 \times 5 \mathrm{~cm})$. The column was developed with six column volumes of chloroform : methanol: ammonium hydroxide: water $(6.5: 2.5: 0.2: 0.2$, by vol.), followed by eight volumes of chloroform:methanol:ammonium hydroxide: water $(10: 10: 0.046: 3$, by vol.). The fractions were checked by TLC (chloroform: methanol:ammonium hydroxide: water; $65: 25: 0.5: 3.5$, by vol.). The fractions containing GlcNAc-PP-DP were pooled and dried. The yield, after quantification of GlcNAc-P-P-DP by preparation of alditol acetates followed by GC-MS analysis, was $0.25 \mathrm{mg}$, providing enough substrate for five microtitre plates using the microtitre plate assay described below. 
Deprotection of per-O-acetylated GIcNAC-P-P-DP. per-OAcetylated GlcNAc-P-P-DP was provided as a gift by Drs Michio Kurosu and Kai Li and prepared by them as described by Kurosu \& Li (2008), using acetylated GlcNAc-1-P (Imperiali \& Zimmerman, 1990) in the coupling reaction with DP. The $O$-acetylated product was purified by preparative TLC (RP-18F254s, Merck) using $0.05 \mathrm{M}$ $\mathrm{NH}_{4} \mathrm{HCO}_{3}$ : THF $(2: 3, \mathrm{v} / \mathrm{v})$. Deprotection was accomplished by treatment with $0.2 \mathrm{M}$ anhydrous sodium methoxide in methanol for $30 \mathrm{~min}$ at room temperature. The mixture was neutralized with Dowex $50\left(\mathrm{H}^{+}\right)$and dried. The final product was stored at $-80{ }^{\circ} \mathrm{C}$ in chloroform: methanol:ammonium hydroxide $(2: 1: 0.003$, by vol.). The identity of the product was verified by negative ion MS (electrospray ionization MS; ESI-MS). The mass spectrum was dominated by the M-1 ion of $\mathrm{m} / z$ 1060.640, which corresponds to a calculated mass of 1060.641 .

Non-microtitre plate enzyme assay. The reaction mixture contained $100 \mathrm{mM}$ TAPS, pH 8.6, $5 \mathrm{mM} \quad \beta$-mercaptoethanol, $10 \mathrm{mM} \mathrm{MgCl} 2,30 \mu \mathrm{M}$ GlcNAc-P-P-DP, $30 \mu \mathrm{M}$ dTDP-Rha, $1.2 \mu \mathrm{M}$ dTDP- $\left[{ }^{14} \mathrm{C}\right]$ Rha (20 000 c.p.m.), $0.1 \% n$-octyl- $\beta$-glucopyranoside and $5 \mu \mathrm{g}$ of membrane proteins in a total volume of $25 \mu \mathrm{l}$. GlcNAc-P-PDP was dried in a test tube and resuspended in $1 \% n$-octyl- $\beta$ glucopyranoside by ultrasound (ultrasound bath, $1 \mathrm{~min}$ ) prior to the addition of other compounds. The reaction was initiated by adding membrane proteins. After incubation at $30{ }^{\circ} \mathrm{C}$ for $30 \mathrm{~min}$ the reaction was quenched by the addition of $1 \mathrm{ml}$ chloroform: methanol $(2: 1, \mathrm{v} /$ v) and $141 \mu \mathrm{l}$ water. After separation of the organic layer from the aqueous layer a portion of the organic layer was subjected to scintillation counting. For TLC, the organic layer was dissolved in chloroform:methanol $(2: 1, \mathrm{v} / \mathrm{v})$ and TLC plates were run in a chloroform:methanol:ammonium hydroxide: water $(65: 25: 0.5$ : 3.5 , by vol.) solvent system. Autoradiography was carried using a phosphoimager system.

Liquid chromatography (LC)-MS of Rha-GICNAC-P-P-DP. LC-MS was performed using an Agilent 6220 TOF spectrometer. A C-18 Xbridge (Waters) HPLC column was used at a flow rate of $0.32 \mathrm{ml}$ $\min ^{-1}$. A gradient was run starting with $5 \mathrm{mM}$ ammonium acetate in methanol and progressing linearly to $5 \mathrm{mM}$ ammonium acetate in $20 \%$ hexane in $n$-propanol over $45 \mathrm{~min}$. The column temperature was $45{ }^{\circ} \mathrm{C}$. The instrument was operated in an electrospray negative ionization mode $\left(\mathrm{ESI}^{-}\right.$) and scanned from 180 to $3200 \mathrm{amu}$. The sample for analysis was prepared as described above with a minor modification. The total volume of the reaction mixture was increased to $100 \mu \mathrm{l}$ and only $2 \mu \mathrm{g}$ of membrane protein was used in the reaction. The incubation time was extended to $1 \mathrm{~h}$. The negative control sample was exactly the same as the positive sample, except that GlcNAc-P-P-DP was omitted.

Kinetic studies. For the determination of apparent $K_{\mathrm{m}}$, substrates were added at various concentrations and protein concentration was reduced to $2 \mu \mathrm{g}$. Incubation times were chosen to obtain initial rate data with conversion to product less than $20 \%$. The apparent $K_{\mathrm{m}}$ values were obtained by a nonlinear regression method using the program Grafit 5.0.

To determine whether WbbL follows a ternary complex reaction mechanism or a double-displacement (ping-pong) mechanism, the reaction velocity over a range of dTDP-Rha and GlcNAc-P-P-DP concentrations at several fixed concentrations of both substrates was measured.

Microtitre plate-based assay. The assay for rhamnosyltransferase was performed in 96-well scintillation plates in a 1450 MicroBeta TriLux microplate scintillation and luminescence counter (PerkinElmer). The reaction mixture contained $100 \mathrm{mM}$ TAPS, $\mathrm{pH} 8.6$, $5 \mathrm{mM} \beta$-mercaptoethanol, $10 \mathrm{mM} \mathrm{MgCl}_{2}, 18 \mu \mathrm{M}$ GlcNAc-P-P-DP,
$35 \mu \mathrm{M}$ dTDP-Rha, dTDP- $\left[{ }^{14} \mathrm{C}\right] \mathrm{Rha}$ (6000 to 25000 c.p.m. depending on the experiment), $0.1 \% n$-octyl- $\beta$-glucopyranoside and $1 \mu \mathrm{g}$ of membrane proteins in a total volume of $25 \mu \mathrm{l}$. GlcNAc-P-P-DP was dried in a test tube and resuspended in $1 \% n$-octyl- $\beta$-glucopyranoside by ultrasound (ultrasound bath, $10 \mathrm{~min}$ ) prior to the addition of $100 \mathrm{mM}$ TAPS, $\mathrm{pH} 8.6,5 \mathrm{mM} \beta$-mercaptoethanol, $10 \mathrm{mM} \mathrm{MgCl}_{2}$ and $1 \mu \mathrm{g}$ of membrane protein. This mixture $(15 \mu \mathrm{l})$ was applied to the wells of the microtitre plate. The reaction was initiated by adding the mixture of dTDP-Rha and dTDP- $\left[{ }^{14} \mathrm{C}\right] \mathrm{Rha}$ in buffer $(10 \mu \mathrm{l})$ and was performed for $15 \mathrm{~min}$ at $30{ }^{\circ} \mathrm{C}$. The reaction was stopped by adding $100 \mu \mathrm{l}$ water-saturated butanol and thoroughly mixed 20 times using a multichannel pipette. Then, $75 \mu$ l Ready Organic scintillation cocktail (Beckman Coulter) was added.

\section{RESULTS}

\section{Cloning and expression of M. tuberculosis Rv3265c}

The analysis of the sequence of Rv3265c by sosuI (http:// bp.nuap.nagoya-u.ac.jp/sosui/sosui_submit.html) indicated that WbbL is a soluble protein, but our data suggested that it is a very tightly associated peripheral membrane protein. After investigation of several systems, expression from pET16b in E. coli (ER2566) produced substantial WbbL in the membrane fraction (Fig. 2). The recombinant protein showed a molecular mass consistent with that predicted for Rv3265c-His-tag $(\sim 34 \mathrm{kDa})$. A small amount of enzyme was also expressed in a soluble form (Fig. 2). Soluble and membrane-bound enzyme was assayed using dTDP- $\left[{ }^{14} \mathrm{C}\right] \mathrm{Rh}$ a and GlcNAc-P-P-DP in the non-microtitre plate assay, as described above (the synthetic form of GlcNAc-P-P-DP was used in most experiments, because of its greater yield). Both soluble and membrane-bound enzymes were active, but the soluble fraction could not be purified via a nickel-affinity column and was not a practical enzyme source. There was no (a)

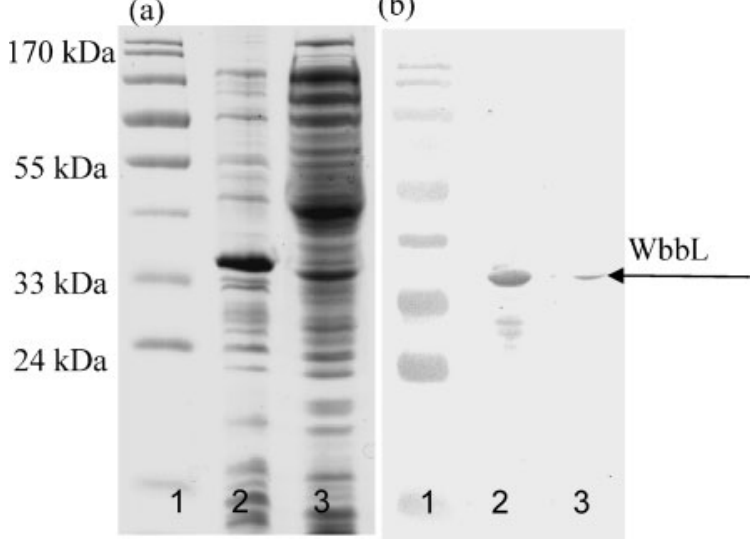

Fig. 2. SDS-PAGE analysis of subcellular fractions from $E$. coli expressing Rv3265c (WbbL) visualized by (a) Coomassie brilliant blue and (b) Western blotting. For both (a) and (b), the lanes are: 1, molecular mass markers; 2, membranes; 3 , cytosol. 
enhancement of soluble enzyme after expression in chaperone-producing strains such as Arctic Express and BL21[DE3]pKJE7. Cloning Rv3265c using the glutathione $S$-transferase (GST) gene fusion system did not improve solubility in a significant way, nor did solubilization from membranes using detergents and/or salts. Thus, the enzyme was used directly in its membrane-associated form.

The identity of the lipid product produced by the membrane-associated enzyme was checked by TLC. A single band was present that migrated to the same extent as a RhaGlcNAc-P-P-DP standard (Fig. 3a). Analysis of WbbL lipid product was performed by negative ion electrospray ionization MS (ESI-MS). The standard reaction sample showed the presence of an M-1 ion at $m / z$ 1206.6921, which corresponds to the calculated Rha-GlcNAc-P-P-DP (minus a proton) mass of 1206.6986 (Fig. 3d, e). This ion was not present in a control sample lacking the acceptor substrate GlcNAc-P-P-DP (Fig. 3b, c).

\section{Determining pH and temperature optima and divalent cation requirements}

Preliminary experiments were carried out to determine suitable conditions for studying the kinetics of and developing a microtitre plate-based assay for WbbL. The enzyme showed optimum activity at $\mathrm{pH} 8.6$ and was absolutely dependent on the presence of divalent cations; the addition of $5 \mathrm{mM}$ EDTA abolished enzyme activity almost completely. Enzyme activity was restored by the addition to buffer containing $5 \mathrm{mM}$ EDTA with $20 \mathrm{mM}$

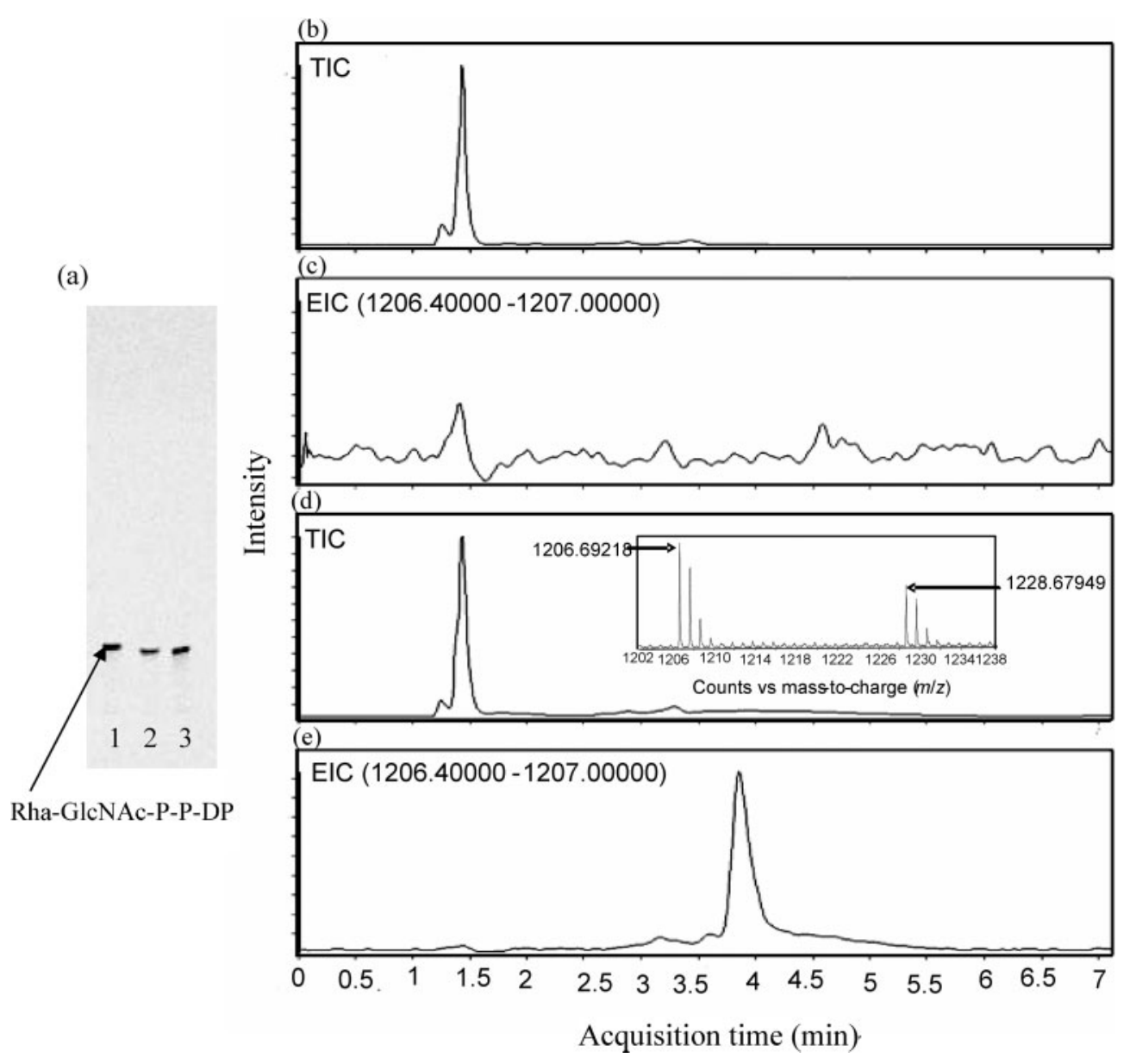

Fig. 3. TLC and LC-ESI-MS analysis of the WbbL lipid product. (a) TLC analysis of organic soluble material obtained after incubation with WbbL expressed in membranes (lane 1) or cytosol (lane 2) of E. coli. A Rha-GlcNAc-P-P-DP standard prepared using M. smegmatis membranes (Mikusova et al., 1996) is also shown (lane 3). Organic soluble material obtained after incubation with membranes was analysed by HPLC-MS (electrospray-negative mode). (b, c) The total ion chromatogram (b) and the $m / z$ 1206 ion chromatogram (c) obtained after injection of the control reaction (no GlcNAc-P-P-DP). (d, e) The total ion chromatogram (d) and the $\mathrm{m} / \mathrm{z} 1206$ ion chromatogram (e) obtained after injection of the complete reaction mixture. The mass spectral region between $\mathrm{m} / \mathrm{z} 1202$ and 1238 is shown as an insert in (d); the ion at $\mathrm{m} / \mathrm{z} 1228$ represents the $\mathrm{M}-2 \mathrm{H}+\mathrm{Na}$ ion. 
$\mathrm{Mg}^{2+}$ or $20 \mathrm{mM} \mathrm{Mn}^{2+}$, but not $20 \mathrm{mM} \mathrm{Ca}^{2+}$. The optimum temperature for activity was found to be $30{ }^{\circ} \mathrm{C}$. It was also found that $\beta$-mercaptoethanol was required for enzyme activity (data not shown).

\section{Kinetic studies}

The kinetic parameters of Rv3265c were investigated using different concentrations of substrates. The apparent $K_{\mathrm{m}}$ for GlcNAc-P-P-DP was found to be $18 \mu \mathrm{M}$ at $35 \mu \mathrm{M}$ dTDPRha, and the apparent $K_{\mathrm{m}}$ for dTDP-Rha was found to be $35 \mu \mathrm{M}$ at $18 \mu \mathrm{M}$ GlcNAc-P-P-DP.

To determine whether WbbL follows a ternary complex reaction mechanism or a double-displacement (ping-pong) mechanism, the reaction velocity over a range of dTDPRha and GlcNAc-P-P-DP concentrations at several fixed concentrations of the other substrate was measured (Table 1a, b). For both substrates, the $K_{\mathrm{m}}$ value remained almost the same over a wide range of concentrations of the other substrate, indicating that the enzyme utilizes a ternary complex mechanism in which the two substrates must bind together to the enzyme. Since substrate inhibition was observed above $60 \mu \mathrm{M}$ for both substrates, kinetic studies were limited to lower concentrations.

\section{Development of a microtitre plate-based assay for rhamnosyltransferase}

We have taken advantage of the organic nature of the product to determine enzymic activity by measuring the

Table 1. (a) Apparent $K_{\mathrm{m}}$ values for GlcNAc-P-P-DP at the indicated concentrations of dTDP-Rha; (b) apparent $K_{\mathrm{m}}$ values for dTDP-Rha at the indicated concentrations of GlcNAc-P-PDP

\begin{tabular}{|cc|}
\hline (a) dTDP-Rha concn $(\boldsymbol{\mu M})^{*}$ & $\boldsymbol{K}_{\mathbf{m}}$ of GlcNAc-P-P-DP $(\boldsymbol{\mu M})$ \\
\hline 20 & $17 \pm 9$ \\
35 & $18 \pm 4$ \\
45 & $16 \pm 3$ \\
50 & $15 \pm 2$ \\
64 & $15 \pm 4$ \\
72 & $16 \pm 3$ \\
\hline$(\mathbf{b})$ GlcNAc-P-P-DP concn & $\boldsymbol{K}_{\mathrm{m}}$ of dTDP-Rha $(\boldsymbol{\mu M})$ \\
$(\boldsymbol{\mu M})^{*}$ & \\
\hline & $35 \pm 10$ \\
10 & $35 \pm 7$ \\
18 & $36 \pm 7$ \\
40 & $33 \pm 17$ \\
50 & $36 \pm 5$ \\
60 & $34 \pm 3$ \\
72 & $33 \pm 12$ \\
80 & $32 \pm 3$ \\
120 & $36 \pm 12$ \\
\hline
\end{tabular}

${ }^{\star}$ Lower and higher concentrations were repeated at least two times. incorporation of the radioactive product $\left[{ }^{14} \mathrm{C}\right] \mathrm{Rha}-$ GlcNAc-P-P-DP into a scintillation cocktail (Ready Organic) that is immiscible with aqueous material. We found that by adding butanol to the microtitre plate wells followed by Ready Organic scintillation cocktail, we could get a satisfactory $(\sim 67 \%)$ counting efficiency for the RhaGlcNAc-P-P-DP product, as determined by comparing Ready Organic/butanol microtitre plate counting with counting the product prepared by the standard extraction protocol. The efficiency of counting a known amount of radioactivity in dTDP- $\left[{ }^{14} \mathrm{C}\right] \mathrm{Rha}$ (determined by standard liquid scintillation counting) in the Ready Organic scintillation cocktail mixed with butanol was very low at only $\sim 1.5 \%$.

The microtitre plate-based assay was run using substrates at their $K_{\mathrm{m}}$ concentrations. To stay in the linear range it was decided to perform a microtitre plate-based assay at $20 \%$ conversion of dTDP- $\left[{ }^{14} \mathrm{C}\right] \mathrm{Rh}$. We then found that DMSO had no negative effect up to at least $2 \%(\mathrm{v} / \mathrm{v})$, and in fact increased the counting efficiency to $80 \%$ (data not shown). We next determined the $Z^{\prime}$ value (Zhang et al., 1999) for the assay using positive (all components including $1 \%$ DMSO) and background controls (same as positive, except lacking enzyme). These data (Fig. 4a) yielded a $Z^{\prime}$ value of 0.83 , indicating an excellent assay. The assay was further validated by demonstrating the inhibition of WbbL activity by dTDP in a dose-dependent manner (Fig. 4b).

\section{DISCUSSION}

WbbL has been classified into family 2 of the GTs with a characteristic fold of superfamily GT-A (http://www.cazy. org/index.html). GT-2 enzymes use an inverting mechanism, as does WbbL, which utilizes dTDP- $\beta$-Rha as a substrate and generates an $\alpha$-rhamnosyl product. Given its inverting mechanism it would be expected to catalyse the attachment of the rhamnosyl residue in an SN2-like fashion. Our kinetic evidence is consistent with this mechanism, as it clearly shows that WbbL forms a ternary complex with both substrates being bound. However, detailed kinetic studies were hampered by substrate inhibition. A similar phenomenon was observed by Zhang et al. (2006) working with Bacillus subtilis TagA, a glycosyltransferase that catalyses a very similar reaction, i.e. the formation of a $\beta$-glycosidic bond between $N$-acetylmannosamine and undecaprenyldiphosphoryl-D- $N$-acetylglucosamine (also inversion, in this case an $\alpha$-sugar nucleotide to a $\beta$-linkage).

An earlier assay for enzymes with lipid-linked acceptors uses a solid-liquid bead-based separation system to selectively adsorb the highly hydrophobic products of the reaction (Hyland \& Anderson, 2003). In contrast, the microtitre plate-based assay herein is based on the distinction between the organic solubility of the WbbL product, Rha-GlcNAc-P-P-DP, and the aqueous solubility of the dTDP-Rha donor, and importantly no 
(a)

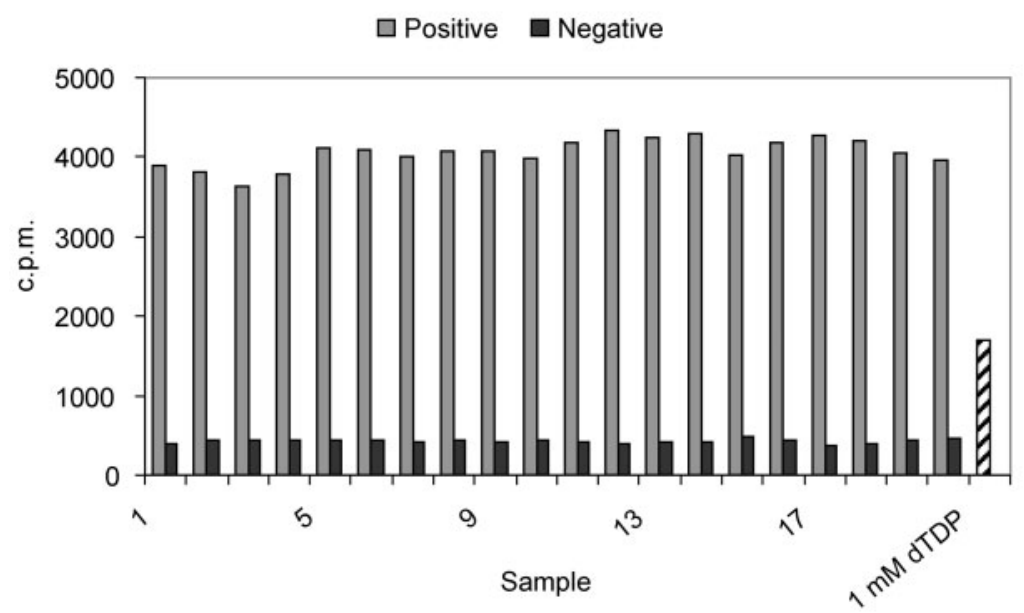

(b)

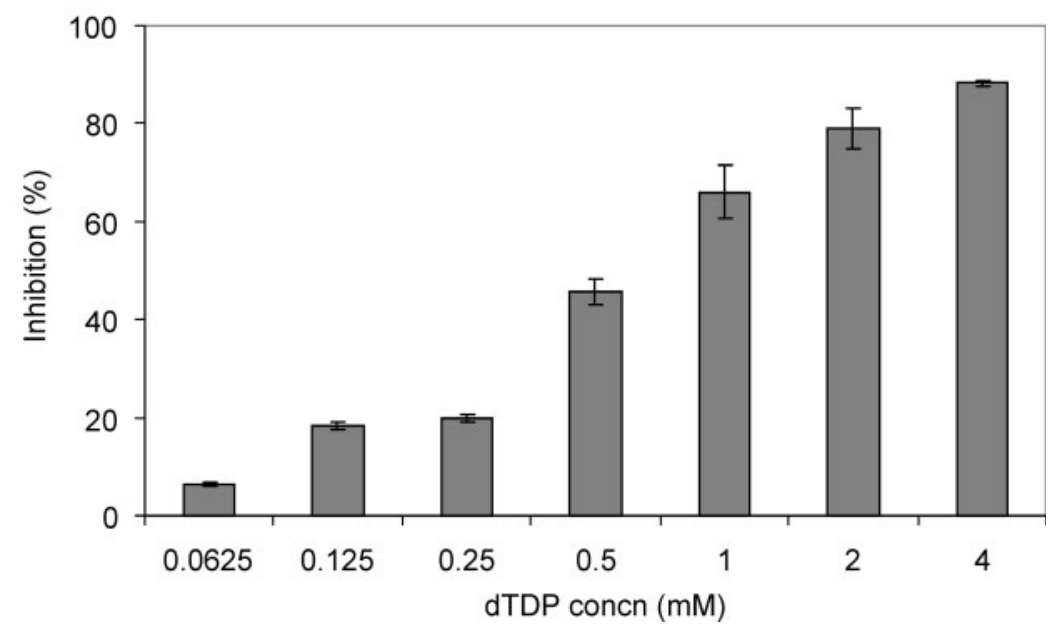

Fig. 4. Validation of a microtitre plate-based assay for WbbL. (a) The $Z^{\prime}$ factor determination for the microtitre plate-based assay was done with 20 positive and 20 negative controls (no enzyme). (b) Titration of dTDP. The assay was performed using $18 \mu \mathrm{M}$ GlcNAc-P-P-DP, $35 \mu \mathrm{M}$ dTDP-Rha, $1.5 \mu \mathrm{M}$ dTDP- $\left[{ }^{14} \mathrm{C}\right] \mathrm{Rha}$ (25000 c.p.m.) and $1 \mu \mathrm{g}$ of membrane proteins. scintillation beads are required. The key component in transferring from an extraction method to direct and selective counting in an organic scintillation cocktail was the addition of butanol to the reaction mixtures; otherwise, little radioactivity was detected, even when radioactive product was present. The microtitre plate assay shows good reproducibility, and should dramatically aid the detection of WbbL inhibitors in new TB drug discovery efforts. Furthermore, this methodology is readily applicable to other enzymes such as TagA that transfer a glycosyl residue from a sugar nucleotide to a lipid-linked substrate.

\section{ACKNOWLEDGEMENTS}

We gratefully acknowledge the gift of synthetic per-O-acetylated GlcNAc-P-P-DP from Kai Li and Michio Kurosu. We also would like to thank Dr Matt Anderson for providing the pET11a-WecA plasmid, Dr Vara Vissa, Colorado State University, for help in constructing truncated WbbL, and Donald Dick for running LC-MS. This work was supported by US Public Health Service Grant NIH-NIAID AI 33706.

\section{REFERENCES}

Hyland, S. A. \& Anderson, M. S. (2003). A high-throughput solidphase extraction assay capable of measuring diverse polyprenyl phosphate:sugar-1-phosphate transferases as exemplified by the WecA, MraY, and MurG proteins. Anal Biochem 317, 156-164.

Imperiali, B. \& Zimmerman, J. W. (1990). Synthesis of dolichypyrophosphate-linked oligosaccharides. Tetrahedron Lett 31, 6485-6488.

Kurosu, M. \& Li, K. (2008). Synthetic studies on Mycobacterium tuberculosis specific fluorescent Park's nucleotide probe. Heterocycles 76 (in press).

Mengin-Lecreulx, D., Texier, L., Rousseau, M. \& Vanheijenoort, J. (1991). The murG gene of Escherichia coli codes for the UDP-Nacetylglucosamine : $N$-acetylmuramyl-(pentapeptide) pyrophosphorylundecaprenol $\mathrm{N}$-acetylglucosamine transferase involved in the membrane steps of peptidoglycan synthesis. J Bacteriol 173, 4625-4636.

Mikusova, K., Mikus, M., Besra, G., Hancock, I. \& Brennan, P. J. (1996). Biosynthesis of the linkage region of the mycobacterial cell wall. J Biol Chem 271, 7820-7828.

Mills, J. A., Motichka, K., Jucker, M., Wu, H. P., Uhlik, B. C., Stern, R. J., Scherman, M. S., Vissa, V. D., Pan, F. \& other authors (2004). Inactivation of the mycobacterial rhamnosyltransferase, which is needed 
for the formation of the arabinogalactan-peptidoglycan linker, leads to irreversible loss of viability. J Biol Chem 279, 43540-43546.

Miroux, B. \& Walker, J. E. (1996). Over-production of proteins in Escherichia coli: mutant hosts that allow synthesis of some membrane proteins and globular proteins at high levels. J Mol Biol 260, 289-298.

Rush, J. S., Rick, P. D. \& Waechter, C. J. (1997). Polyisoprenyl phosphate specificity of UDP-GlcNAc: undecaprenyl phosphate $\mathrm{N}$-acetylglucosaminyl 1-P transferase from E.coli. Glycobiology 7, 315-322.
Zhang, J. H., Chung, T. D. Y. \& Oldenburg, K. R. (1999). A simple statistical parameter for use in evaluation and validation of high throughput screening assays. J Biomol Screen 4, 67-73.

Zhang, Y. H., Ginsberg, C., Yuan, Y. Q. \& Walker, S. (2006). Acceptor substrate selectivity and kinetic mechanism of Bacillus subtilis TagA. Biochemistry 45, 10895-10904.

Edited by: M. Daffé 